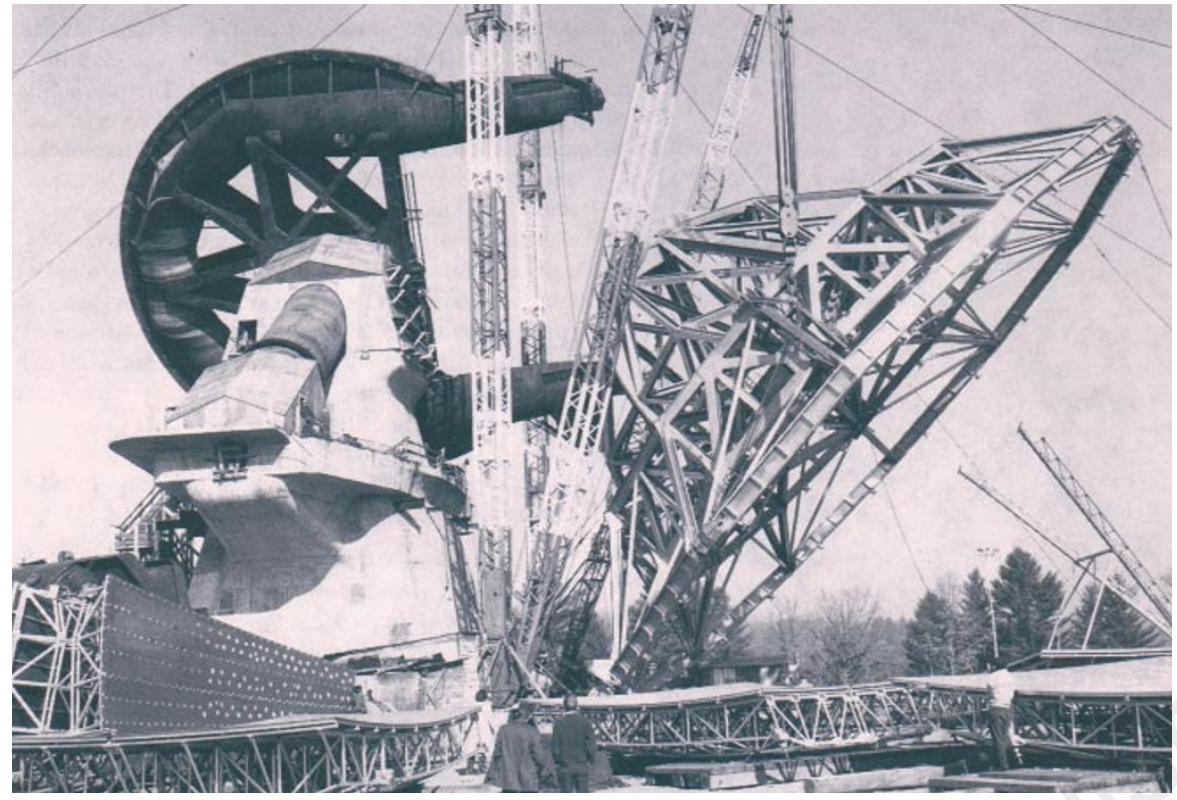

Sky eye: raising the superstructure of the 140-ft telescope at Green Bank in the 1960s.

\section{History repeats itself}

The History of Radio Astronomy and the National Radio Astronomy Observatory

by Benjamin K. Malphrus

Krieger: 1996. Pp. 210. \$49.50, 244.50

\section{Leslie Sage}

As a long-time user of telescopes at the US National Radio Astronomy Observatory (NRAO), I was eager to read this book to learn more about my 'scientific origins'. I was very disappointed by it; the discussion seems shallow as both science and history.

The emphasis is on the development of the NRAO site at Green Bank, West Virginia, along with some historical background. Most of the text is about the (now collapsed) $300-\mathrm{ft}$ telescope and the recently closed $140-\mathrm{ft}$ telescope, but there is a very brief chapter containing sections about the $36-\mathrm{ft}$ telescope at Kitt Peak in Arizona, the Very Large Array in New Mexico, and the new Green Bank Telescope, which is the replacement for the 300-ft antenna. The MillimetreWave Array is not mentioned at all.

Although the author discusses extensively the scientific results obtained from the older telescopes, he does so in a way so laden with jargon that only an astronomer could understand them. Moreover, he does not explain why the results are (or at least were) interesting in terms of advancing our physical understanding of the Universe. Rather, the discussion is about phenomenology, so that even optical astronomers may sometimes be left in the dark about why the observations were made.

I was struck by the lack of historical analysis. There are parallels between the building of the 140-ft telescope and the new Green
Bank Telescope, which has run into similar delays in construction. I feel that the author is doing a disservice to the astronomical community by not exploring the underlying issues, although I imagine that there are some who would prefer not to have such problems aired in public. As George Santayana said: "Those who cannot remember the past are condemned to repeat it."

The story of NRAO, and its companion organization at optical wavelengths (the National Optical Astronomy Observatories), is one that deserves to be told to a wide audience, as the two have revolutionized how astronomy is done, not just in the United States, but throughout the world. By giving telescope time based on the scientific merit of the ideas, rather than the institutional affiliation of the observer, they have led to the field exploding over the past 40 years, and to a revolution in our knowledge of the Universe. I wish this book had done a better job of telling that story.

Leslie Sage is an assistant editor of Nature.

\section{corrections}

- In I. J. Good's review of The Conscious Universe by Dean Radin (Nature 389, 806;

1997), an editorial addition led to an

innaccurate statement being attributed to

the author rather than to the sceptical

psychologist Mark Hansel. The fourth

sentence in the penultimate paragraph

should have read: "Radin quotes Hansel as

saying that three $P$ values, each of 0.01 ,

amount to one of $10^{-6}$, and that he (Hansel) would find that convincing."

- Some of the bibliographical details for Embryology: Constructing the Organism edited by Scott F. Gilbert and Anne M.

Raunio (Nature 391, 857; 1998) were given incorrectly. The book has 513 pages, not 240 , and is published in hardback only.

\section{New in paperback}

\section{The Killing of the Countryside}

by Graham Harvey

Vintage, £7.99

Looks at the current state of farming in Britain, and makes the case for a sustainable future.

\section{The Complete Fables of Aesop}

Translated by Olivia and Robert Temple, with an introduction by Robert Temple

Penguin, £5.99, $\$ 8.95$

First English translation ever to make available the complete corpus of 358 fables. The stories provide fascinating glimpses of ordinary life in ancient Greece, and include satirical tales of alien creatures - apes, camels, lions and elephants which presumably originated in Libya and Egypt.

\section{The Conscious Mind: In Search of a Fundamental Theory}

by David J. Chalmers

Oxford University Press, £9.99

"Chalmers's dualism is a very mild one and does not invoke any spooky soul-stuff", C. Koch,

Nature 381, 123 (1996).

\section{The Machinery of Life}

by David S. Goodsell

Copernicus, $\$ 19.50$

"The drawings are among the most instructive one can find in structural biology, and the mechanisms of life are elegantly explained.... The genius of the book is in its simplicity.... Important insights are stated succinctly and boldly.... The most elegant mechanisms are presented in an easily accessible but consistently informative way", H. P. Erickson, Nature 365, 306 (1993).

\section{Darwin's Dreampond: Drama in Lake Victoria}

by Tijs Goldschmidt

MIT Press, $\$ 15$

"Goldschmidt was part of the Dutch haplochromine ecology survey team that devoted more than 20 years to collecting baseline ecological, morphological, taxonomic and fisheries data on the cichlids, which provide the basic protein source for the people around Lake Victoria.... [His] book is both unusual and eminently readable. He alternates between personal narrative... and scientific passages", Axel Meyer, Nature 383, 590 (1996).

\section{Hal's Legacy: 2001s Computer as Dream and Reality}

edited by David G. Stork, with a foreword by Arthur C. Clarke

\section{MIT Press, $\$ 17.50$}

Brings together science and pop culture. Contributions by various scientists include essays on supercomputer design with regard to speech synthesis, common-sense reasoning, emotions, lip reading and chess playing. 
atheoretical diagnostic language — is thus given further support.

While denying that they are 'antipsychiatry', Kutchins and Kirk do deplore the proliferation of psychiatric labelling, facilitated by DSM's ever-lengthening diagnostic list. Nowadays many groups, and not just psychiatrists, patently have an interest in translating everyday behaviours into psychiatric diseases - worry for example becomes "generalized anxiety disorder".

In this medicalization process, the wretched and the powerless are all too easily further victimized by labels that carry a lasting stigma. One solution, of course, would be for the public acceptance, without shame, of mental disorder. But that would be crying for the moon.

This is a serious and well-documented study, which casts serious doubt on the touted scientific status of DSM categories. It is also readable, although Kutchins and Kirk's preoccupation with the day-to-day minutiae of the politics of naming may dispose some psychiatrists to see in this a case of ancient obsessional disorder. It is certainly sobering to discover just how the terms we take for truth have come into currency.

Roy Porter is at the Wellcome Institute for the

History of Medicine, 183 Euston Road, London

NW1 2BE, UK.

email:r.porter@wellcome.ac.uk

\section{Where has the billion trillion gone?}

\section{The Conscious Universe: The Scientific Truth of Psychic \\ Phenomena}

by Dean I. Radin

HarperEdge: 1997. Pp. 320. \$25.

\section{I.J.Good}

My friend Christopher R. Evans worked for a time with the well-known parapsychologist J. B. Rhine, but became a sceptic. In 1974 I invited Evans to Blacksburg, Virginia, to give a lecture on extra-sensory perception (ESP), and picked him up at Roanoke airport. $\mathrm{He}$ had travelled from London in a Boeing 727. The licence number of my car happened to be CRE 727. The probability of that coincidence was about $1 / 26^{3} \times 1,000 \approx$ $1 / 17,000,000$.

I have experienced three even more remarkable coincidences, one of which changed the course of my life. But I doubt whether these coincidences were paranormal because there are more than 5 million minutes a decade. Some people must have experienced chance coincidences with probabilities of about $10^{-14}$. So controlled, not anecdotal, observations are needed.

In England, for about 20 years starting in 1939, S. G. Soal was by far the most promi-

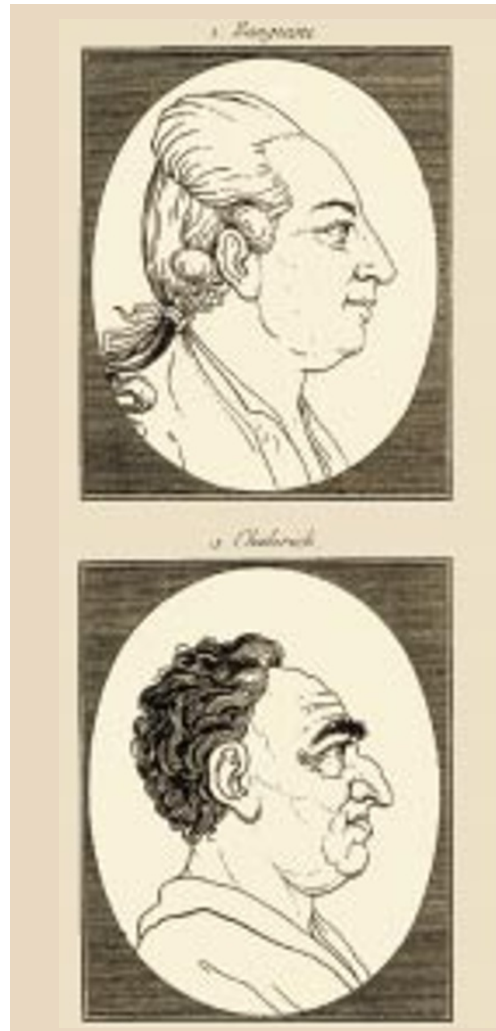

\section{Body language}

Facial features of the sanguine, phlegmatic, melancholic and choleric personality types (clockwise from top left), taken from Johann Lavater's Essays on Physiognomy (1789). They are reproduced in Believing in Magic: The Psychology of Superstition by Stuart A. Vyse

nent parapsychologist. He did controlled card-guessing experiments resembling those of Rhine. At the suggestion of Whateley Carington, Soal examined his records, looking for 'hits' one ahead and one behind the guess of the 'current' card. In one series of experiments, the tail probability, or $P$ value (the probability that, by chance, the outcome would be at least as 'extreme' as the observed outcome), was $10^{-35}$ for the 'one-aheads', thus seeming to prove the existence of precognitive telepathy.

But evidence accumulated, culminating in the ingenious detective work of Betty Markwick in 1978, showing that Soal's studies were very probably fraudulent. Dean Radin, author of The Conscious Universe, avoids mentioning Soal.

Radin is firmly convinced that paranormal events happen. His conviction is based mainly on evidence from controlled experiments but is influenced also by the "nonlocal' phenomena of quantum mechanics.

Quantum mechanics has affected many people's metaphysical speculations about consciousness and ESP. For example, some 50 years ago, in a conversation with the prominent physicist Léon Rosenfeld about subjective experiences, I said: “A [quantum]

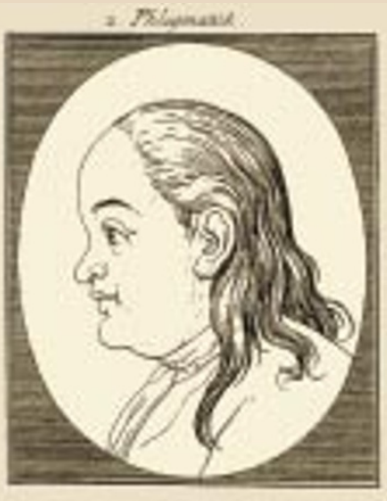

W. Vhably

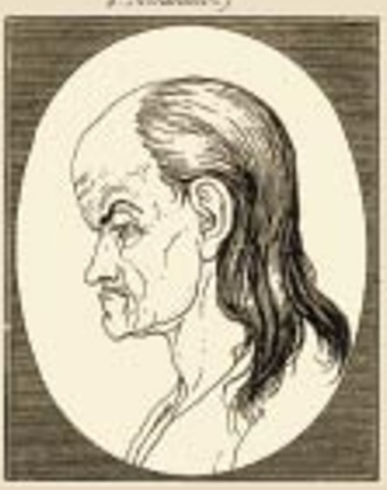

(Oxford University Press, £18.99, \$25). Vyse argues that scientific analysis of differences in personality traits - such as sensitivity to coincidence, fear of failure, a need for control can help us to understand why superstition and belief in the paranormal are so prevalent today.

field theory does seem to be natural in order to understand how the activities of numerous neurons in a brain somehow summate. Perhaps psi depends on $\psi$ [the Schrödinger wave function]."

Leaving psi aside, there are much more serious and technical speculations about the relationship between consciousness and quantum fields by Stuart Hameroff and Roger Penrose, related to microtubules extremely small skeletal elements in neurons. One could say that microtubules update Descartes' pineal gland. Penrose does not, however, mention ESP in his work on consciousness.

Taken at its face value, some of the evidence from controlled experiments is conclusive. But we have to allow for fraud and the 'file-drawer' effect. Take the first of these. Even many 'normal' scientists have cheated, as recorded by Alexander Kohn in False Prophets: Fraud and Error in Science and Medicine (Barnes and Noble, 1986). To that collection may be added the psychologists who lie to their subjects and call the lying 'experimental dissimulation'.

Parapsychologists and psychics have more incentive to cheat because, if their research results are uninteresting, they have 
less opportunity to turn to teaching. Unconscious cheating, wishful thinking (which is universal), unsound experimental design and analysis, and seeing what we expect are further pitfalls. The statistician M. G. Kendall once described the phenomenon of seeing what one expects as "one of the deadliest forms of bias in psychology". He was referring to an experiment in which an observer of a reliable random-number generator had a tendency to write down too many even numbers.

Potentially the most important evidence in Radin's book is in the chapter on metaanalysis, which is also emphasized in the introduction - and it is here that the 'filedrawer' effect comes into play.

Meta-analysis is the combination of results from many experiments. A problem in meta-analysis, and in statistics generally, is how to allow for the researches that remain unpublished and unknown because their $P$ values did not reach a conventional significance level such as 0.05 . I do not know who coined the name 'file-drawer' effect for this problem. This effect drags down the statistical significance of published work. Radin claims that "parapsychologists were among the first to become sensitive to this problem" - although he does not say when - and he mentions that "in 1975 the Parapsychological Association's officers adopted a policy opposing the selective reporting of positive outcomes". The problem was known to statisticians by 1958 .

Consider the following typical example. Radin points out that there were 186 publications on ESP card tests worldwide from 1882 to 1939 . "The combined results of this four-million trial database [taken at face value]," he says, "translate into tremendous odds against chance - more than a billion trillion to one." (A 'trial' is the guess of one card.) He means that the $P$ value is about $10^{-21}$ - he is not writing only for the scientific establishment. This $P$ value corresponds to a bulge above 'chance' expectation of $9.5 \sigma$, where $\sigma$ is the standard deviation. (I call that a 'sigmage' of 9.5.)

Apart from the possibility of conscious and unconscious fraud and wishful thinking in some fraction of the publications, Radin claims, with no explanation, that, in order to "nullify" the statistical significance, the file drawer would have to contain "more than 3,300 unpublished, unsuccessful reports for each published report". That number 3,300 is a gross overestimate. It should be reduced at least to about 15 (or even to 8 ).

The expected sigmage in the file drawer, under the null hypothesis, would be slightly negative but I will call it zero. If these results were combined with the published work, the total sample size would be multiplied by 16, thus becoming 64 million individual guesses. Given the null hypothesis ('chance'), the bulge would be unaffected so the sigmage would be divided by $\sqrt{ } 16=4$ and would become $9.5 / 4=2.4$, with a $P$ value of about $1 / 100$.

Because the number of individual guesses is so large, this $P$ value appreciably supports the null hypothesis (no ESP). This is because a Bayes factor (the factor by which the odds of a hypothesis are multiplied in the light of the observations), corresponding to a fixed $P$ value, is roughly proportional to $1 / \sqrt{ } \mathrm{N}$, where $\mathrm{N}$ is the sample size. So Radin's method for evaluating the file-drawer effect, whatever that method may be, must be misguided. This conclusion largely undermines Radin's meta-analysis which is central to his case for ESP.

Nevertheless, Radin's book is well written and provides a good summary of the arguments supporting the existence of ESP, with about 600 references. It is less good on the counter-arguments. Readers should also consult ESP and Parapsychology: A Critical Evaluation by C. E. M. Hansel (Buffalo, 1980), where much fraudulent work is exposed. Radin quotes Hansel as saying that three $P$ values, each of 0.01 , amount to one of $10^{-6}$, and that he (Radin) would find that convincing. But the product of independent $P$ values is not a $P$ value. The product has to be transformed by a method due to $\mathrm{R}$. A. Fisher. Both Hansel and Radin have overlooked this. In the present example, the composite $P$ value is $1 / 9,000$, not $1 / 1,000,000$.

I am not a sceptic by definition. There is one type of experiment that could convince me if it were successful. Guesses, by psychics, of the parities (even or odd) of future cricket scores could be published on the World Wide Web. The actual scores and parities could be published (later) in large print to help the

\section{Toy review Smaller, cheaper, more plasticky}

With Christmas still months away, and the latest Mars landing already fading in the memory, it is a good time to draw your attention to this scientific stocking-filler. In collaboration with the US Jet Propulsion Laboratory, Mattel has brought out the "Mattel Hot Wheels JPL Sojourner Mars Rover Action Pack Set".

This is a set of three small plastic models: the Pathfinder spacecraft in transit, with removable heat shield and tiny lander; a larger-scale version of the lander, with foldable panels and removable rover; and a larger-scale-still Sojourner rover. The rover is undoubtedly the star, with sprung 'rocker-bogey' suspension that allows it to take up all sorts of cute rock-sniffing postures.

The Nature review copy of the Mattel Hot Wheels JPL Sojourner Mars Rover Action Pack Set has now completed its primary mission objectives, successfully demonstrating the technology involved in operating for several weeks on top of a computer screen in a harsh environment of editorial curiosity, without suffering any appreciable reduction in its precognizing of the psychics and to help their evaluation. This procedure would rule out the possibility of undetectable fraud.

I. J. Good is in the Department of Statistics,

Virginia Polytechnic Institute and State University, Blacksburg, Virginia 24061-0439, USA.

\section{Dangerous liaisons}

\section{Menachem's Seed}

by Carl Djerassi

University of Georgia Press: 1997. Pp. 196. $\$ 21.95$

\section{Jack Cohen}

This is the third novel in a series of what the chemist Carl Djerassi calls "science-infiction" in which everything mentioned could or does exist. "Most of my characters, fictional as well as real, are scientists," he says. "By exposing their lives, I try to make comprehensible the culture and behaviour of scientists."

There is a similar, specialized genre on the fringes of modern science fiction - stories about fictional scientists like fictional detectives or even fictional cowboys. Carl Sagan's Contact is a well known example, but Gregory Benford's Timescape or Artefact, Greg Bear's Blood Music, as well as Nigel Kneale's older Quatermass series or even E. E. 'Doc' Smith's archaic Lensman all come to mind as fiction about scientists. Science-infiction, however, seems to be less exciting and to have fewer possibilities.

I reviewed elsewhere the first of Djerassi's novels, Cantor's Dilemma, and recom-

mended it, 1

mainstrean 


\section{Old embryos and new developments}

\section{Principles of Development}

by LewisWolpert with Rosa Beddington,

Jeremy Brookes and Thomas Jessell

Current Biology/Oxford University Press:

1998. Pp. 484. £25.95, $\$ 65$

\section{Embryology: Constructing the Organism \\ edited by Scott F. Gilbert and \\ Anne M. Raunio \\ Sinauer: 1997. Pp. 240. \$69.95, £32.95(hbk),

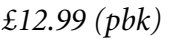

\section{Jonathan Slack}

Twenty years ago it was possible to pick up two textbooks of developmental biology written by different authors and find almost no common ground in the contents. That was because, as recently as the 1970s, there were profound disagreements about what the basic questions of development actually were, and what sort of things we might accept as a satisfactory explanation.

To some, it was all about the nuts and bolts of the control of gene expression, to others it was all about cell movement, and there was even a small group to whom it was really a matter of guarding the true faith of classical experimental embryology, in the hope that future generations would have the means to solve the problems.

But those days are gone and the basic problems are now solved, at least in principle. Today, when we pick up a textbook and flip through it, we find pretty much what we expect to find. This consensus means that the subject has reached maturity. In the past 20 years we have und erstood things that were previously mysterious, and we understand them well enough to have some confidence in relaying the findings to undergraduates.

Lewis Wolpert and his co-authors have been at the forefront of the revolution that has brought the subject so far. Principles of Development is an ambitious attempt to capture the world undergraduate market from the main competition, Scott Gilbert's Devel opmental Biology, now in its fifth edition. In this regard he has the advantage of starting afresh, whereas Gilbert's book has evolved from a first edition written when the subject was in a far less secure state. As someone who has recently had to design some undergraduate courses, I think Wolpert has done well, both in relation to the selection of which topics to include and in the level of detail at which they are presented.

The book starts by introducing the model organisms on which most developmental biology research is done: Xenopus, the chick, the mouse, the zebrafish, Drosophila, Caenorhabditis elegans and Arabidopsis. The next few chapters cover the formation of the

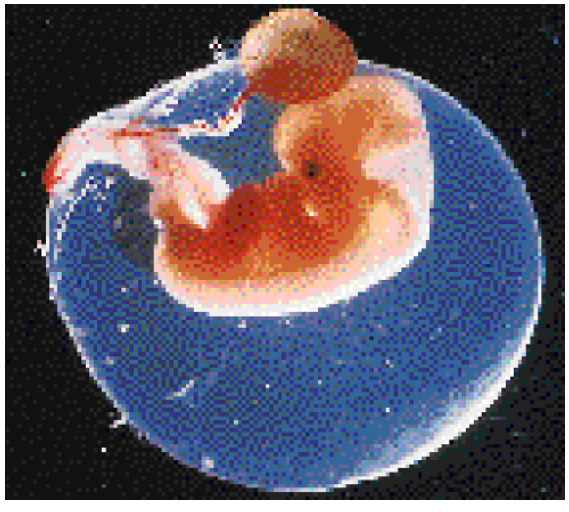

Embryologist in the making? A six-week human embryo.

basic body plan and include topics such as mesoderm induction, somitogenesis and Drosophila developmental genetics. Then there is a quick gallop through selected topics in a variety of non-Drosophila invertebrates and plants, before a return to vertebrates for various subjects including morphogenetics movements, cell differentiation, sex determination and neuronal development. I was surprised to find that "organogenesis" consists almost entirely of the limb and Drosophila discs, as there are, after all, a lot of organs in the vertebrate body apart from the limb. As usual, the last chapter deals with the evolution of developmental mechanisms, known in the trade as "Evo-Devo".

The book uses a consistent style of coloured illustration throughout that is the hallmark of the co-publisher Current Biology. These figures are mainly very clear and attractive, although in a few places the number and brightness of colours can impede appreciation of the content.

Students often find developmental biology difficult. This is partly because they now tend to have a poor knowledge of animal structure, so the necessary minimum of descriptive morphology is all totally new to them. It is also because developmental biology is essentially a synthesis of anatomy, molecular biology and genetics. Students are used to learning one thing at a time, and it can be confusing to jump from a genetic cross to a signal transduction pathway to an altered anatomy all in a few minutes.

Wolpert has taken great care to make things as clear and simple as he can but the subject is still challenging. To take a random example: "As a result of Toll receptor activation cactus protein is degraded and nolonger binds the dorsal protein, which is then free to enter the nuclei. In embryos lacking cactus protein almost all the dorsal protein is found in the nuclei; there is a very poor concentration gradient and the embryos are ventralized." A research developmental biologist will absorb such a sentence immediately, but a student busy with other subjects from receptor biochemistry to animal behaviour needs to have it unpacked slowly and methodically. A way to keep things simple is to stick to one organism at a time. This book contains several chapters that jump around between the seven organisms and require the reader to have instant recall of many names of genes and body parts. For this reason it may not be quite as clear as it first seems.

Gilbert, author of the present standard textbook on developmental biology, has found time, with Anne Raunio, to edit a completely different kind of book: Embryol ogy: Constructing the Organism. At first sight the title might seem a needless risk, as everyone knows that the word "embryology" sounds old-fashioned to American ears, and in today's cut-throat world no academic book can afford to seem old-fashioned. But Gilbert has clearly planned this as a resource for the rapidly g rowing field of Evo-Devo, because it is a phylum-by-phylum account of the descriptive embryology of animals.

'Descriptive embryology' is what people used to do in the nineteenth century, before 'experimental embryology' was invented, and it means just describing what you can see happening down the microscope. This may sound very boring, but in fact it grows on you, and nobody can possibly understand anything about the development of an organism without a firm grasp of its descriptive embryology. In the past, anyone who wanted to know about this in an animal other than the six models had to find a copy of Kumé and Dan's Invertebrate Embryology (1957), which was almost unobtainable until it was reprinted by Garland in 1988, and is once again out of print.

Gilbert's book covers all the major animal phyla and also some of the minor ones for which the available information is hardly sufficient for a whole chapter (such as the lophophorate phyla). The approach is fiercely comparative, so the chapter about insects does not dwell too long on Drosophila, and that about mammals finds space for monot remes and marsupials as well as the mouse. There is even a token chapter on plants, which does not confine itself to Arabidopsis but mentions bryophytes and pteridophytes as well.

Although entirely in black and white, the illustrations are excellent and make this an attractive book. B ecause of its vast scope it contains a lot of very interesting stuff. I am always impressed by our ignorance of the mechanisms of asexual reproduction by budding, as enjoyed by many cnidarians, bryozoans and tunicates. This is a problem unsolved even in principle. I am also amazed by my own ignorance of so many things known to other people, but thanks to Gilbert I am now at least acquainted with the "groping penis" of the barnacle.

I am struck by the fact that, despite the relative obscurity of its contents, the book is fairly easy reading compared with Wolpert's, as there is no need here to understand the 
complex genetic pathways involving repression of repressors. Students who find modern developmental biology difficult would find it a lot easier if they had mastered this material first. So logically they should be required to take a course in descriptive animal emb ryology using Gilbert's book, and then progress to developmental biology I and II using Wolpert's.

However, the appetite for animal structure in most places is so small that I suspect this could happen only in universities with a very strong zoology programme. In most places Gilbert's book is likely to be relegated to small but eager graduate classes studying Evo-Devo. Still, as the autho rs claim in the preface, this is a "timeless" book and it will still be useful when fashions change.

Jonathan Slack is in the Department of Biology and Biochemistry, University of Bath, Bath BA2 7AY, $U K$.

\section{The great elusionist}

\section{The Elusive Neutrino: A Subatomic \\ Detective Story}

\section{by Nickolas Solomey}

W. H. Freeman/Scientific American Library: 1997. Pp. 206. $\$ 34.95, £ 19.95$

\section{Stephen Battersby}

The manner in which a nothing-particle was first reluctantly proposed and then triumphantly displayed is one of the truly excitingadventures of science.

This is from Isaac Asimov's The Neutrino (1966), an early predecessor of Nickolas Solomey's new book, The Elusive Neutrino. Asimov does tell an exciting story, speeding through much of the history of science to explain what conservation laws are and why they are important. Only then does he describe how three such laws - the conservation of energy, momentum and angular momentum - led Wolfgang Pauli to postulate the existence of the neutrino in 1931.

The biggest problem of the day in particle physics was that the energy and momentum sums in beta decay (a form of radioactivity) didn't add up. Pauli realized that the problem could be solved by assuming that a new particle was escaping undetected from experiments, carrying away energy, momentum and angular momentum, but with no charge and little or no mass. The neutrino (little neutral one) came to be a vital part of particle physics, and eventually any lingering discomfort at this 'cheat' was removed when physicists detected the particle directly. That detection paved the way for neutrino astronomy, which was just beginning in 1966.

In the 30 years since Asimov's book, a revolution in fundamental physics has taken place. In the Standard Model of particle physics, three types of neutrino, three types of electron

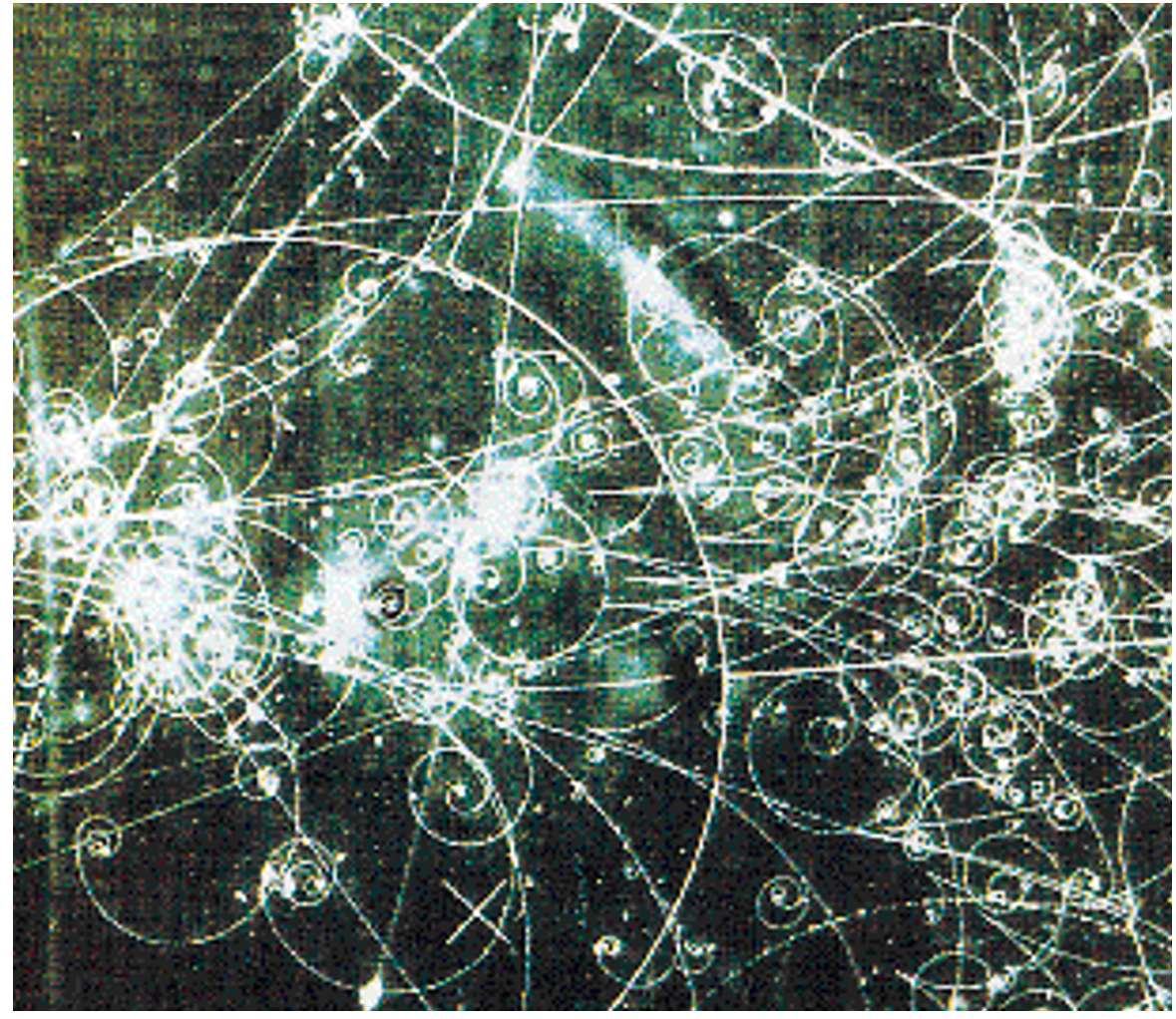

Image-makers: tracks left by the many different particles produced in a natrino reaction.

and six types of quark interact by exchanging various force-carrying particles. And neutrino astronomy has produced results: a puzzling deficit of observed neutrinos from the Sun is well established, and, as Asimov hoped, neutrinos have been seen from a supernova (in 1987).

In the past couple of years, there have even been hints that neutrinos have mass, a property that could explain the solar neutrino deficit and the large-scale structure of the Universe and would constitute a step beyond the Standard Model.

In The Elusive Neutrino, Solomey's goals are necessarily greater than Asimov's because of these huge advances in our understanding. In any case, Asimov has few peers as a science writer, so it is unfair to compare the new book with the earlier. Unfair, but irresistible.

More than halfway though The Neutrino comes chapter seven, "Enter the neutrino". At that point in the proofs, Asimov's editor wrote "At last!". But that's the way it stayed. Solomey's book might have benefited from similar restraint. Asimov knew that his readers needed educating before they could understand the significance of the neutrino, as shown by his chapter titles: "Momentum", "Energy", "Atomic structure", "Mass-energy", "Electric charge". Solomey, instead, skates over the basics in chapter one, getting all the way to Fermi's four-point theory of beta decay. Then in chapter two he plunges straight into one of the more speculative topics in the book, "Cosmology and the neutrino mass". Perhaps Solomey thought a long introduction would bore the reader.
Another problem is that, like beta decay, parts of the book do not add up: vital particles of meaning seem to be escaping undetectably. Explanations are routinely let down by the language. It is not just a matter of distracting infelicities ("somewhat close proximity", "not as fully complete", "was impinged on the fluorescent screen"); it is often language careless enough to confuse or misinform the lay reader.

In the introduction, Solomey mentions the electron, proton and neutron, and then "particles that are even more elementary: quarks and leptons". The electron is a lepton, so here it is rendered more elementary than itself. Time reversal for macroscopic objects is "forbidden outright" (to contrast with "might not be plausible" for particles) and then in the next parag raph becomes "not a plausible occurrence". Later we read that "Because [random number generators] never repeat a sequence of numbers, they are as unpredictable as a roulette wheel". That is just nonsense.

The book is wide-ranging and, for the most part, informative - enough to make it fairly interesting. The only parts I found dull might reasonably interest an experimental physicist: Solomey is meticulous in apportioning credit for the various discoveries, and he describes scores of experiments in detail. He also discusses many of the experiments that got it wrong, or were not sensitive enough to be definitive. Surely two or three of these would have been enough to make the point that science is a messy process? $\square$ Stephen Battersby is an assistant editor at Nature. 
petrology, microscopy and tree-ring studies.

Every step of the way Dillehay has anticipated possible objections and been careful to explain, describe and evaluate not only his methodology but also the smallest category of potential evidence. For example, no less than 1,461 pieces of charcoal were examined for spatial distribution, degree of charring and identification, where possible, of wood taxa. This level of recording yielded valuable insights into the selection of specific kinds of wood for fuel, and the use of fire for cooking, heating and tool manufacture.

From such detail comes the realization that Monte Verde is one of those rare books that, as an impressive and influential scholarly achievement, set a benchmark for all future work.

Nicholas J. Saunders is in the Department of Anthropology, University College London, Gower Street, London WC1E 6BT, and the Department of Archaeology, University of Southampton,

Highfield, Southampton SO17 1BJ, UK.

\section{The trouble with sex}

\section{Sex on the Brain: The Biological Differences Between Men and Women}

by Deborah Blum

Viking: 1997. Pp. 329. \$24.95

\section{Melissa Hines}

It is hard to write a good book about psychological sex differences. The topic is relevant to attitudes and social policy in many areas, including who should take primary responsibility for childcare, whether education should differ for girls and boys, whether laws should prohibit certain sexual practices, and to what extent choice of occupation is dictated by sex.

The scope of this book is broad. For a general idea of its factual accuracy, I looked at its coverage of my own research areas: sex differences in the human brain and the role of androgen and oestrogen in shaping gender development. Here the disappointment began.

A simple example is whether prenatal exposure to high concentrations of androgen ('male' hormone) improves mathematical ability. In this book Deborah Blum says that it does, suggesting that prenatal brain programming by hormones causes males to excel at mathematics. But the only two existing studies of the relationship between prenatal androgen and mathematical ability found impaired ability.

The trouble with sex is that people, scientists and non-scientists alike, have their own theories about how men and women differ. Developmental psychologists call these theories 'gender schemas' and find that they influence memory. For example, children shown pictures of male nurses and female doctors later confidently recall seeing female nurses and male doctors. Those writing popular books on psychological sex differences often seem to have similar problems with remembering research findings.

The book relies heavily on theories from evolutionary psychology. These theories are difficult to test empirically and are particularly prone to contamination by gender schemas. They seem sensible only because they correspond to popular preconceptions. For instance, Blum describes a theory that men prefer blondes because men are evolutionarily predisposed to prefer youthful mates, and blondness is a sign of youth. But the blondness of youth usually disappears by puberty.

If preference for blondes reflects an evolutionary predisposition to youthful mates, men would be predisposed to paedophilia. If this suggestion seems more absurd than the original, it is because prevailing gender schemas suggest that men have innate preferences for young women but not children.

The book also suffers from a failure to screen information for reliability. Everything, from replication of results in refereed journals, through presentations and comments at scientific conferences, to reports in the popular press, is given equal credibility. This casual approach to facts, combined with phrases like "those nitpicky cell-counting studies", left me feeling as if I had eaten too much junk food.

Some might argue that accuracy is unimportant, because a popular book can stimulate interest in a research area. But facts do matter. Take again the supposed androgeninduced predisposition to mathematical ability. Research into attitudes and performance shows that an assumption of inability can become a self-fulfilling prophecy. This misinformation itself could therefore impair mathematical performance in girls and women.

Research into psychological sexual differentiation has produced surprising findings that sometimes contradict prevailing gender schemas. For instance, although we think of sex as being determined by the sex chromosomes (XX or XY), their role is minor compared with that of gonadal hormones. Also, although hormones from the male gonads are essential for masculine development, hormones from the female gonads have relatively little influence on feminine psychological development. Even more remarkably, what we think of as the major 'female' hormone, oestrogen, can have powerful masculinizing influences during development. For further information consult scientific publications, but mind your gender schemas.

Melissa Hines is in the Department of Psychology, City University, Northampton Square, London EC1VOHB, UK.
New in paperback

One River: Science, Adventure and Hallucinogenics in the Amazon Basin by Wade Davis

Simon and Schuster, £7.99

Reviewed in Nature 384, 229 (1996)

\section{The Conscious Mind}

by David J. Chalmers

Oxford University Press, $£ 9.99$

Reviewed in Nature 381, 123 (1996)

Humphry Davy: Science and Power

by David Knight

Cambridge University Press, £16.95, \$27.95

Reviewed in Nature 359, 785 (1992)

Infinite Potential: The Life and Times of David Bohm

by F. David Peat

Helix, $\$ 16$

Reviewed in Nature 385, 592 (1997)

The End of the World: The Science and Ethics of Human Extinction

by John Leslie

Routledge, £9.99

Reviewed in Nature 380, 296 (1996); see also

Nature 387, 338 (1997)

Catastrophism: Asteroids, Comets, and Other Dynamic Events in Earth History

by Richard Huggett

Verso, £14, $\$ 19$

Original 1990 edition reviewed in Nature 345, 778 (1990)

Bats: Biology and Behaviour by John D. Altringham Oxford University Press, $£ 17.99$

\section{Corrections}

- The full list of co-authors of Principles of Development by Lewis Wolpert (reviewed in Nature 391, 857; 1998) should have read: Rosa Beddington, Jeremy Brockes, Thomas Jessell, Peter Lawrence and Elliot Meyerowitz. - Some lines dropped off Derek Fordham's review of Nansen (Nature 391, 137; 1998). The sixth paragraph should start: "When it became clear the Fram would not drift over the North Pole, Nansen and Hjalmar Johansen left the ice-locked vessel at latitude $84^{\circ} 4^{\prime}$ and attempted to reach the pole over the ice. They turned back at latitude $86^{\circ}$ 14', having established a new farthestnorth record...".

- In the review of Next of Kin (Nature 390, 246; 1997), an editorial change rendered the fictitious veterinarian "Dr Dolittle" (John) as "Dr Doolittle" (Eliza). 


\section{Old embryos and new developments}

\section{Principles of Development}

by Lewis Wolpert with Rosa Beddington, Jeremy Brookes and Thomas Jessell Current Biology/Oxford University Press: 1998. Pp. 484. £25.95, $\$ 65$

\section{Embryology: Constructing the Organism}

edited by Scott F. Gilbert and

Anne M. Raunio

Sinauer: 1997. Pp. 240. \$69.95, £32.95(hbk),

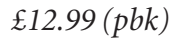

\section{Jonathan Slack}

Twenty years ago it was possible to pick up two textbooks of developmental biology written by different authors and find almost no common ground in the contents. That was because, as recently as the 1970s, there were profound disagreements about what the basic questions of development actually were, and what sort of things we might accept as a satisfactory explanation.

To some, it was all about the nuts and bolts of the control of gene expression, to others it was all about cell movement, and there was even a small group to whom it was really a matter of guarding the true faith of classical experimental embryology, in the hope that future generations would have the means to solve the problems.

But those days are gone and the basic problems are now solved, at least in principle. Today, when we pick up a textbook and flip through it, we find pretty much what we expect to find. This consensus means that the subject has reached maturity. In the past 20 years we have understood things that were previously mysterious, and we understand them well enough to have some confidence in relaying the findings to undergraduates.

Lewis Wolpert and his co-authors have been at the forefront of the revolution that has brought the subject so far. Principles of Development is an ambitious attempt to capture the world undergraduate market from the main competition, Scott Gilbert's Developmental Biology, now in its fifth edition. In this regard he has the advantage of starting afresh, whereas Gilbert's book has evolved from a first edition written when the subject was in a far less secure state. As someone who has recently had to design some undergraduate courses, I think Wolpert has done well, both in relation to the selection of which topics to include and in the level of detail at which they are presented.

The book starts by introducing the model organisms on which most developmental biology research is done: Xenopus, the chick, the mouse, the zebrafish, Drosophila, Caenorhabditis elegans and Arabidopsis. The next few chapters cover the formation of the

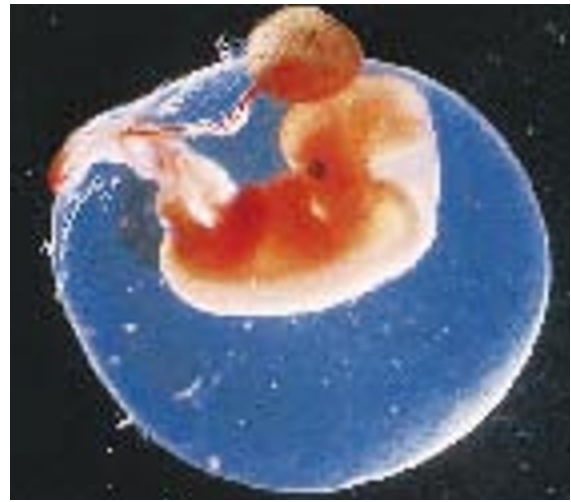

Embryologist in the making? A six-week human embryo.

basic body plan and include topics such as mesoderm induction, somitogenesis and Drosophila developmental genetics. Then there is a quick gallop through selected topics in a variety of non-Drosophila invertebrates and plants, before a return to vertebrates for various subjects including morphogenetics movements, cell differentiation, sex determination and neuronal development. I was surprised to find that "organogenesis" consists almost entirely of the limb and Drosophila discs, as there are, after all, a lot of organs in the vertebrate body apart from the limb. As usual, the last chapter deals with the evolution of developmental mechanisms, known in the trade as "Evo-Devo".

The book uses a consistent style of coloured illustration throughout that is the hallmark of the co-publisher Current Biology. These figures are mainly very clear and attractive, although in a few places the number and brightness of colours can impede appreciation of the content.

Students often find developmental biology difficult. This is partly because they now tend to have a poor knowledge of animal structure, so the necessary minimum of descriptive morphology is all totally new to them. It is also because developmental biology is essentially a synthesis of anatomy, molecular biology and genetics. Students are used to learning one thing at a time, and it can be confusing to jump from a genetic cross to a signal transduction pathway to an altered anatomy all in a few minutes.

Wolpert has taken great care to make things as clear and simple as he can but the subject is still challenging. To take a random example: "As a result of Toll receptor activation cactus protein is degraded and no longer binds the dorsal protein, which is then free to enter the nuclei. In embryos lacking cactus protein almost all the dorsal protein is found in the nuclei; there is a very poor concentration gradient and the embryos are ventralized.” A research developmental biologist will absorb such a sentence immediately, but a student busy with other subjects from receptor biochemistry to animal behaviour needs to have it unpacked slowly and methodically. A way to keep things simple is to stick to one organism at a time. This book contains several chapters that jump around between the seven organisms and require the reader to have instant recall of many names of genes and body parts. For this reason it may not be quite as clear as it first seems.

Gilbert, author of the present standard textbook on developmental biology, has found time, with Anne Raunio, to edit a completely different kind of book: Embryology: Constructing the Organism. At first sight the title might seem a needless risk, as everyone knows that the word "embryology" sounds old-fashioned to American ears, and in today's cut-throat world no academic book can afford to seem old-fashioned. But Gilbert has clearly planned this as a resource for the rapidly growing field of Evo-Devo, because it is a phylum-by-phylum account of the descriptive embryology of animals.

'Descriptive embryology' is what people used to do in the nineteenth century, before 'experimental embryology' was invented, and it means just describing what you can see happening down the microscope. This may sound very boring, but in fact it grows on you, and nobody can possibly understand anything about the development of an organism without a firm grasp of its descriptive embryology. In the past, anyone who wanted to know about this in an animal other than the six models had to find a copy of Kumé and Dan's Invertebrate Embryology (1957), which was almost unobtainable until it was reprinted by Garland in 1988, and is once again out of print.

Gilbert's book covers all the major animal phyla and also some of the minor ones for which the available information is hardly sufficient for a whole chapter (such as the lophophorate phyla). The approach is fiercely comparative, so the chapter about insects does not dwell too long on Drosophila, and that about mammals finds space for monotremes and marsupials as well as the mouse. There is even a token chapter on plants, which does not confine itself to Arabidopsis but mentions bryophytes and pteridophytes as well.

Although entirely in black and white, the illustrations are excellent and make this an attractive book. Because of its vast scope it contains a lot of very interesting stuff. I am always impressed by our ignorance of the mechanisms of asexual reproduction by budding, as enjoyed by many cnidarians, bryozoans and tunicates. This is a problem unsolved even in principle. I am also amazed by my own ignorance of so many things known to other people, but thanks to Gilbert I am now at least acquainted with the "groping penis" of the barnacle.

I am struck by the fact that, despite the relative obscurity of its contents, the book is fairly easy reading compared with Wolpert's, as there is no need here to understand the 
complex genetic pathways involving repression of repressors. Students who find modern developmental biology difficult would find it a lot easier if they had mastered this material first. So logically they should be required to take a course in descriptive animal embryology using Gilbert's book, and then progress to developmental biology I and II using Wolpert's.

However, the appetite for animal structure in most places is so small that I suspect this could happen only in universities with a very strong zoology programme. In most places Gilbert's book is likely to be relegated to small but eager graduate classes studying Evo-Devo. Still, as the authors claim in the preface, this is a "timeless" book and it will still be useful when fashions change.

Jonathan Slack is in the Department of Biology and Biochemistry, University of Bath, Bath BA2 7AY, $U K$.

\section{The great elusionist}

\section{The Elusive Neutrino: A Subatomic Detective Story \\ by Nickolas Solomey \\ W. H. Freeman/Scientific American Library: 1997. Pp. 206. \$34.95, £19.95}

\section{Stephen Battersby}

The manner in which a nothing-particle was first reluctantly proposed and then triumphantly displayed is one of the truly exciting adventures of science.

This is from Isaac Asimov's The Neutrino (1966), an early predecessor of Nickolas Solomey's new book, The Elusive Neutrino. Asimov does tell an exciting story, speeding through much of the history of science to explain what conservation laws are and why they are important. Only then does he describe how three such laws - the conservation of energy, momentum and angular momentum - led Wolfgang Pauli to postulate the existence of the neutrino in 1931.

The biggest problem of the day in particle physics was that the energy and momentum sums in beta decay (a form of radioactivity) didn't add up. Pauli realized that the problem could be solved by assuming that a new particle was escaping undetected from experiments, carrying away energy, momentum and angular momentum, but with no charge and little or no mass. The neutrino (little neutral one) came to be a vital part of particle physics, and eventually any lingering discomfort at this 'cheat' was removed when physicists detected the particle directly. That detection paved the way for neutrino astronomy, which was just beginning in 1966.

In the 30 years since Asimov's book, a revolution in fundamental physics has taken place. In the Standard Model of particle physics, three types of neutrino, three types of electron

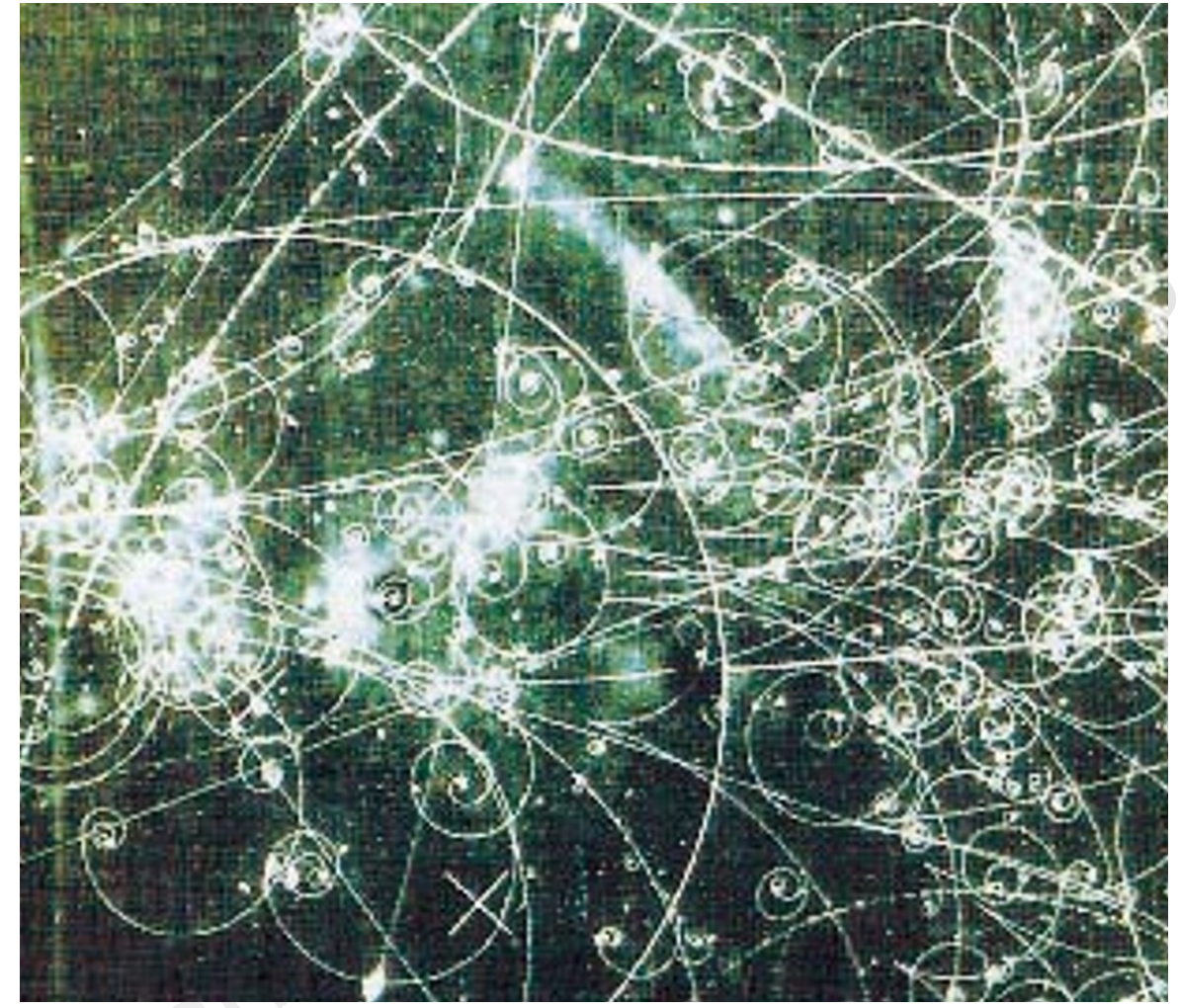

Image-makers: tracks left by the many different particles produced in a neutrino reaction.

and six types of quark interact by exchanging various force-carrying particles. And neutrino astronomy has produced results: a puzzling deficit of observed neutrinos from the Sun is well established, and, as Asimov hoped, neutrinos have been seen from a supernova (in 1987).

In the past couple of years, there have even been hints that neutrinos have mass, a property that could explain the solar neutrino deficit and the large-scale structure of the Universe and would constitute a step beyond the Standard Model.

In The Elusive Neutrino, Solomey's goals are necessarily greater than Asimov's because of these huge advances in our understanding. In any case, Asimov has few peers as a science writer, so it is unfair to compare the new book with the earlier. Unfair, but irresistible.

More than halfway though The Neutrino comes chapter seven, "Enter the neutrino". At that point in the proofs, Asimov's editor wrote "At last!". But that's the way it stayed. Solomey's book might have benefited from similar restraint. Asimov knew that his readers needed educating before they could understand the significance of the neutrino, as shown by his chapter titles: "Momentum", "Energy", "Atomic structure", "Mass-energy", "Electric charge". Solomey, instead, skates over the basics in chapter one, getting all the way to Fermi's four-point theory of beta decay. Then in chapter two he plunges straight into one of the more speculative topics in the book, "Cosmology and the neutrino mass". Perhaps Solomey thought a long introduction would bore the reader.
Another problem is that, like beta decay, parts of the book do not add up: vital particles of meaning seem to be escaping undetectably. Explanations are routinely let down by the language. It is not just a matter of distracting infelicities ("somewhat close proximity", "not as fully complete", "was impinged on the fluorescent screen"); it is often language careless enough to confuse or misinform the lay reader.

In the introduction, Solomey mentions the electron, proton and neutron, and then "particles that are even more elementary: quarks and leptons". The electron is a lepton, so here it is rendered more elementary than itself. Time reversal for macroscopic objects is "forbidden outright" (to contrast with "might not be plausible" for particles) and then in the next paragraph becomes "not a plausible occurrence". Later we read that "Because [random number generators] never repeat a sequence of numbers, they are as unpredictable as a roulette wheel". That is just nonsense.

The book is wide-ranging and, for the most part, informative - enough to make it fairly interesting. The only parts I found dull might reasonably interest an experimental physicist: Solomey is meticulous in apportioning credit for the various discoveries, and he describes scores of experiments in detail. He also discusses many of the experiments that got it wrong, or were not sensitive enough to be definitive. Surely two or three of these would have been enough to make the point that science is a messy process? $\square$ Stephen Battersby is an assistant editor at Nature. 


\section{The long walk northwards}

\section{Nansen: The Explorer as Hero}

by Roland Huntford

Duckworth: 1997. Pp.598. £25

\section{Derek Fordham}

"Strange there is always sadness on departure. It is as if I cannot after all bear to leave this bleak waste of ice, glacier, cold and toil." Fridtjof Nansen's sentiments when he returned in 1896 from his journey across the Arctic Ocean reveal something of the restless melancholic nature of this outstanding explorer and statesman, the subject of Roland Huntford's latest work in a series that has so far included Roald Amundsen, Robert Scott and Ernest Shackleton.

Nansen had already made the first crossing of Greenland in 1888, and began his rise from being a moderately successful career scientist, researching into the central nervous system, to becoming one of the great innovators who changed the face of polar exploration. He was at his best when he elected to strike across Greenland from the virtually unknown east coast, thereby eliminating any temptation to turn back, with "Death or the west coast" as his motto.

Suspended between snow and sky in the unknown white heart of Greenland, his expedition marked a revolution in the concept of exploration. The Victorian romantic ideal of enduring suffering as accomplishment was superseded by what Nansen called merely "a ski trip". In Norway he was borne along on a wave of national fervour, and within 18 months he had married, undertaken several lecture tours, written The First Crossing of Greenland, and begun to plan his next expedition.

The North Pole was the next objective, and Nansen stood a reigning concept on its head by planning to deliberately freeze a specially designed boat, the Fram, into the ice north of Siberia and then be carried by the transpolar drift over the North Pole. He felt he would thus "take note of the forces of nature and work with them".

This was a dangerous and lengthy project, and Huntford meticulously shows how Nansen's turbulent, unpredictable nature seriously threatened harmony on board Fram, but was balanced by the steadfastness of Otto Sverdrup, his companion from Greenland and the ship's master. They were characters defined by the distinction between personality and leadership. Nansen was the man with drive, Sverdrup with the talent for command.

When it became clear that Fram would not drift over the North Pole, Nansen and Hjalmar Johansen left the ice-locked vessel at latitude $84^{\circ} 14^{\prime}$, having established a new farthest-north record, and began a hair-

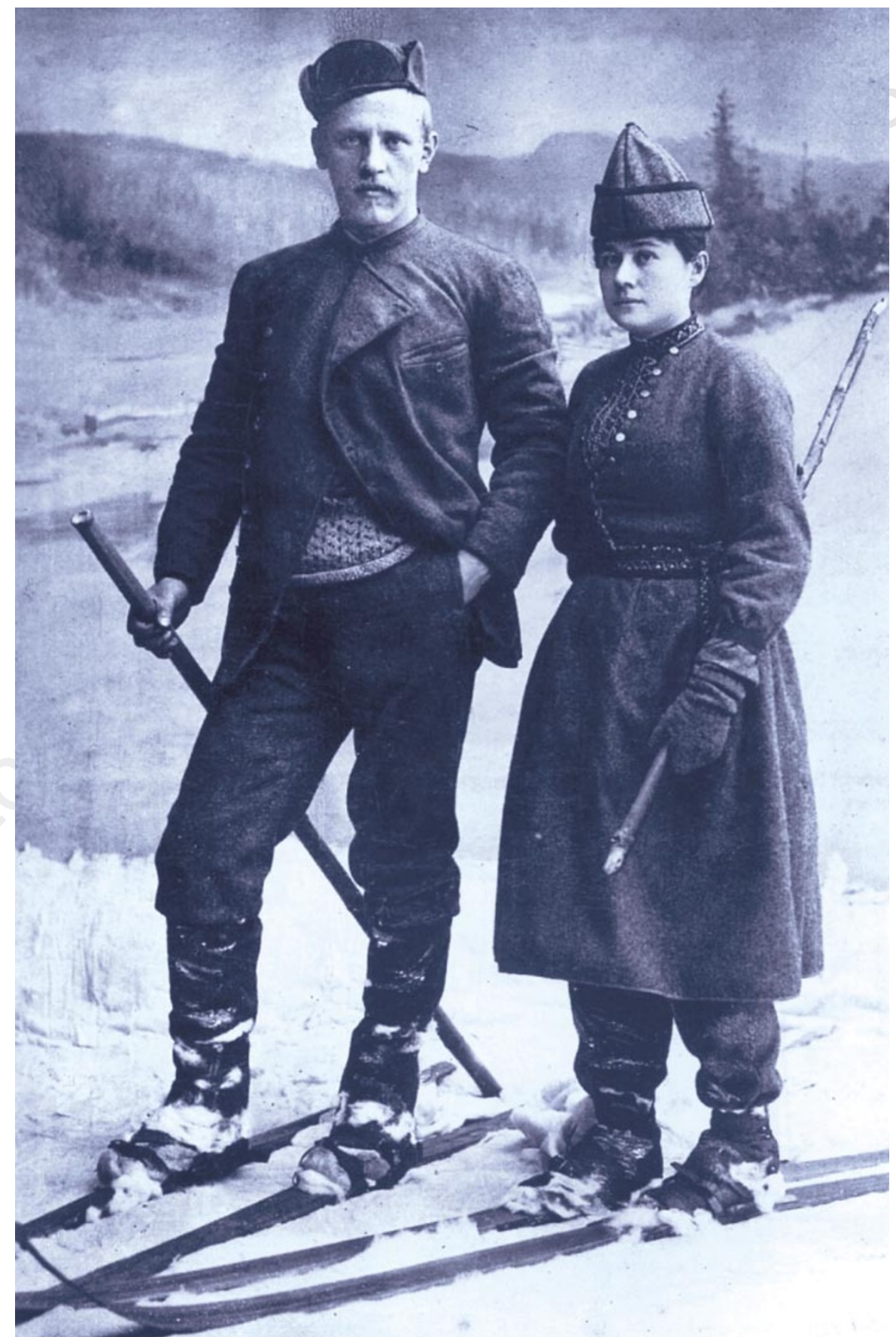

Nansen and his wife Eva, pictured soon after their marriage, not in the Arctic but in a studio pose.

raising, hazardous journey of nearly 400 miles across the shifting, breaking ice of the Arctic Ocean towards Franz Josef Land, the position of which had not yet been precisely established.

With no idea where they were when they found land, Nansen and Johansen built a windowless stone hut in which a hibernatory third polar winter was spent, still sharing the same sleeping-bag and still not on first-name terms. In the spring of 1896 some basic instinct drove them south rather than to the west where they thought Spitsbergen and salvation lay.

Dogs were heard, a man was seen, and Nansen met Frederick Jackson, leader of the North Pole expedition sponsored by the English newspaper magnate Albert Harmsworth, in an Arctic version of the encounter between Stanley and Livingstone. Against all odds, Nansen had turned defeat into victory. Since leaving Fram, he and Johansen had travelled 700 miles across the polar ice and had met Jackson just before 


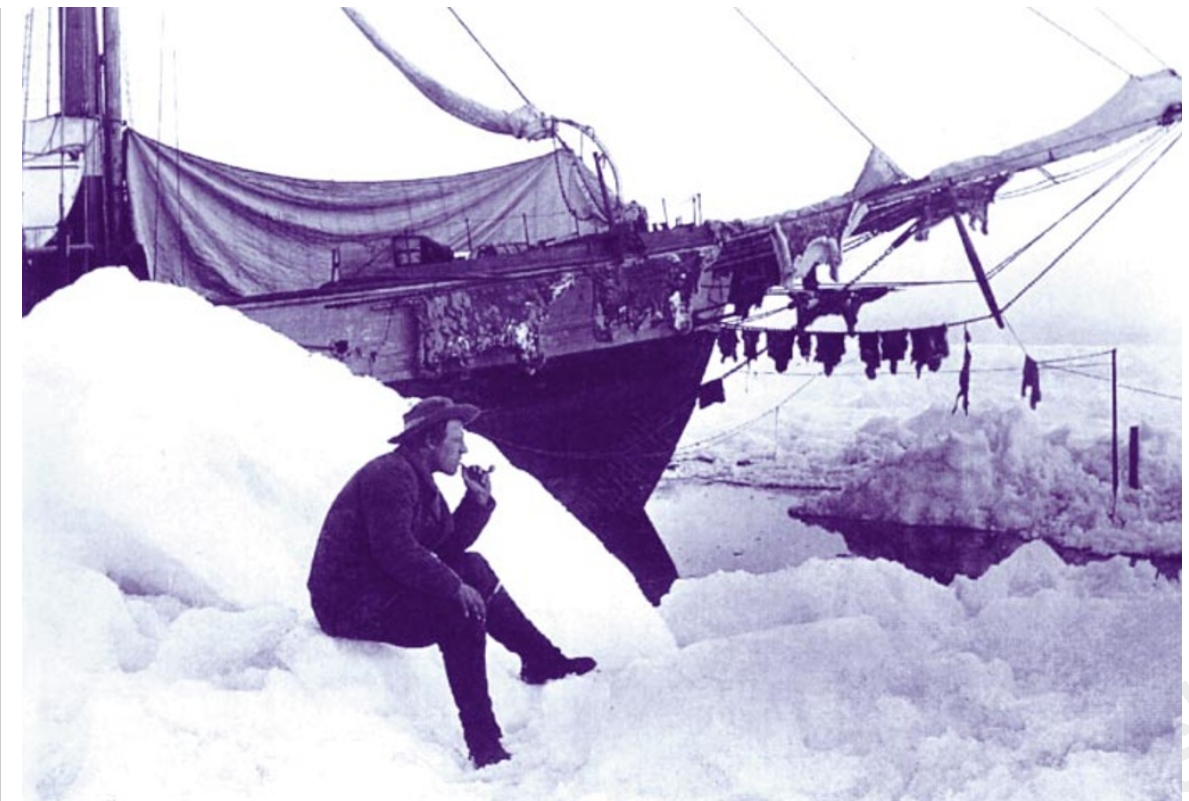

In the summer of 1894, Nansen's vessel Fram is still heading north, destined to fall short of the pole.

attempting the crossing to Spitsbergen which they might well not have survived.

Regarding his farthest-north record as under threat, Nansen was anxious to capitalize on it as quickly as possible, and lecture tour followed lecture tour. His absences, following his three years in the Arctic, did nothing to re-establish relations with his wife.

Then in 1900 came the news he had dreaded, that the Italian explorer Amadeo had reached $86^{\circ} 33^{\prime}$ north. Nansen's farthestnorth record had stood for only five years. $\mathrm{He}$ suffered a further blow when Amundsen reached the South Pole - the objective Amundsen had set himself - for, despite the acclaim Nansen received, he had not reached his own objective, the North Pole. At the age of 40 he needed a role.

He left the world of his Arctic triumphs and, in between various romantic affairs, entered a tumbling kaleidoscope of diplomacy and statesmanship of ever-increasing complexity. Norwegian independence, the League of Nations food and refugee relief and repatriation of prisoners of war all fell into the hands of this great Viking statesman. Despite all the international machinations associated with this work, and the accompanying encounters with Lenin, Trotsky and Stalin, Nansen's integrity and stature enabled him to achieve much and brought him the Nobel peace prize in 1922.

A few years before his death in 1930 he was elected rector of St Andrew's University in Scotland. In his inaugural address he fondly reminisced about his Arctic days and quoted Henrik Ibsen's dictum "that man is strongest who stands alone". Huntford brings vividly to life the enigma of a man who stood alone in so many ways as a giant among men but was unsure enough of himself to describe his nature as "a chaos of disharmony".

Nansen was not a leader of men but he could, when he chose, inspire them. Having made an Arctic journey without equal, he opened the age of modern polar exploration and inspired his successors. He was the stuff of Columbus, Magellan and the Vikings of old. His tragedy was that he was born out of place and out of time.

Nansen emerges, as have so many of the great explorers, as a very complex character. He was much more than the "explorer as hero" of the subtitle. Of Nansen it could surely be more accurately said "the elements so mixed in him that nature might stand up to all the world and say, 'This was a man!'”. $\square$ Derek Fordham is at 66 Ashburnham Grove, Greenwich, London SE10 8UJ, UK.

\section{Mental devices}

\section{Evolution in Mind}

by Henry Plotkin

Allen Lane: 1997. Pp. 276. £25

\section{Massimo Piattelli-Palmarini}

The name of the game in cognitive science today is evolutionary psychology. In addition to Henry Plotkin's new book, recent years have seen the publication of many accomplished popularizations of the field, including Steven Pinker's How the Mind Works, Terrence Deacon's The Symbolic Species, Michael Gazzaniga's Nature's Mind, Daniel Dennett's Darwin's Dangerous Idea and Kinds of Minds, and Richard Dawkins' Climbing Mount Improbable. These authors cite one another frequently, being close allies and, in some cases, personal friends. The list is by no means exhaustive, and ignores professional papers in the specialized journals.

Most of these books are well crafted, often crisp, at times peppy, and occasionally infuriating to cognitive scientists of a differ- ent persuasion. The authors have created a scientific-literary genre, as well as a new subfield of psychology. Academics in other specializations are advised to leaf through at least one of these volumes before going to lunch at the faculty club. Would it not be mildly embarrassing to be found ignorant of evolutionary psychology?

Evolution in Mind is as good a point of entry as any, indeed it has been written precisely for this purpose. Plotkin is a leading exponent of the philosophical school known as 'evolutionary epistemology' (that is, the evolution of knowledge) and has proved in the past, in more scholarly works, to be the kind of experimental psychologist who feels perfectly at ease conversing with the giants of philosophy. His new work is terse and engaging, avoiding not only details and technicalities but also sensationalism and flippancy. It is, in a way, a concise encyclopaedia of psychology - if by psychology one means the natural science of the mind, with a strong emphasis on the word natural.

According to Plotkin, the theory of evolution is the Atlantis of psychology. After the death of William James, a whole Darwinian continent has been lost for psychology, and has to be made to resurface. The evolutionary geneticist Theodosius Dobzhansky used to say that nothing in biology makes sense except in the light of evolution. Plotkin modifies this motto slightly, claiming that "in psychology nothing makes complete sense except in the light of evolution" (his emphasis). By judiciously grafting selfishgene theory, game theory, behavioural ecology and neural networks onto mainstream cognitive science, he provides a fine introductory textbook not only to evolutionary psychology but also to modern psychology in general.

I, for one, siding more with structurally oriented modularity theorists such as Noam Chomsky and Jerry Fodor (who hold that our cognitive abilities are products of innate organs of mind, and whose work the book brilliantly expounds), disagree with Plotkin on only two crucial points. First, because the modularity of mind seems to be not only true, but also arguably (as Plotkin stresses) the most important discovery of modern cognitive science, there is no justification for his alignment with authors who for some reason desire to go 'beyond' modularity, even at the price of smuggling back useless remnants of the defeated theory of 'general intelligence'.

Second, we are still waiting for an example of genuine psychological explanation that descends easily from evolutionary insights but would remain inaccessible to mainstream structural-computational cognitive science. Leda Cosmides and John Tooby, two largely unsung heroes of Plotkin's book, have tried hard to account for our strange and spontaneous conditional 
Jupiter missiles within a matter of months. Robert Kennedy insisted to Dobrynin that this assurance should remain secret and that, if the Soviet Union made it public, the assurance would be withdrawn. President Kennedy was thus able to earn a reputation for toughness while showing flexibility and a willingness to compromise. The agreement on the Jupiters remained secret for many years - although the missiles were removed in 1963.

President Kennedy did not believe that Khrushchev wanted war, any more than he did himself. He believed that Khrushchev wanted to redress the nuclear balance to put pressure on the Western powers in Berlin. In recent years the most common interpretation has been that Khrushchev wanted to defend Cuba against a US attack.

Aleksandr Fursenko and Timothy Naftali do not resolve this issue in their book. The way they set up their account gives pride of place to the defence of Cuba, but they also provide evidence to show Khrushchev's concern about the way in which the Soviet delay in deploying strategic missiles hampered his foreign policy.

Fursenko and Naftali bring new evidence from Russian archives to bear on the crisis. They show that relations between the Soviet Union and Castro's regime were close and complex before the crisis. They argue that Khrushchev was in charge of Soviet policy during this period, and that whatever was erratic about Soviet policy sprang not from political struggles inside the Kremlin but from Khrushchev's own personality.

They also indicate that Robert Kennedy's conversation with Dobrynin about the Jupiters was not decisive in resolving the crisis, because Khrushchev had already decided to agree to withdrawal of the Soviet missiles from Cuba before he learned of Kennedy's assurance that the Jupiters would be withdrawn from Turkey.

Although they provide a great deal of new information, Fursenko and Naftali do not say enough about the sources they have used. They have been able to consult documents in the Russian Presidential Archive, to which access is very restricted. But they do not reveal what collections they could consult. They quote few documents at length, even though they evidently used minutes of Politburo meetings. One reason why these questions matter is that if the authors had access only to collections dealing specifically with Cuba, that would lead to an emphasis on the defence of Cuba as a motive for Khrushchev's actions. Interesting though the new Soviet sources are, they do not compare in quality with the Kennedy tapes. This suggests that we still have more to learn about the Cuban missile crisis.

David Holloway is at the School of Humanities and Sciences, Stanford University, Stanford, California 94305-2070, USA.

\section{Ape people}

\section{Next of Kin: What Chimpanzees} Have Taught Me About Who We Are by Roger Fouts with Stephen Tukel Mills Morrow: 1997. Pp. 420. \$25

\section{Marc D. Hauser}

The philosopher Ludwig Wittgenstein argued that even if lions could speak we wouldn't understand them. The psychologist David Premack mused that even if chickens had syntax, they'd have nothing interesting to say. But what if both these arguments are wrong, leaving the possibility that, like the fictitious veterinarian Dr Doolittle, we can talk to animals and learn interesting things about their lives? And if we could, whose lives would be worth learning about? If you were a psychologist interested in the human mind without doubt, be driven towards our closest living relative: the chimpanzee.

Roger Fouts is a psychologist. Next of Kin, written with Stephen Tukel Mills, is Fouts's personal account of what it is like to work captive chimpanzees. It is an adventure story rife with sadness and horror, excitement and intrigue. It begins with his childhood experia child psychologist and, finally, his involvement as a graduate in experimental psycholand its evolutionary history, you would, with, talk to and defend the lives and rights of ences with animals, his dreams of becoming

ogy with the ground-breaking research of Allen and Beatrix Gardner and their newly acquired chimpanzee, Washoe.

The Gardners began a research programme designed to reveal the linguistic potential of chimpanzees, specifically the ability to learn words in American sign language (ASL) and to string them together into novel, syntactically structured sentences. Fouts's apprenticeship involved caring for Washoe, treating her like a human child albeit a deaf child who needed to learn ASL rather than spoken language. The job turned into a life-long passion and led to a fervent interest in the care and well-being of captive animals.

In the late 1960s and early 1970s, several research programmes sparked a renewed interest in human nature and the attributes that had long been touted as uniquely human. Jane Goodall's studies of chimpanzees in the Gombe Reserve were beginning to mature, uncovering evidence of tool use, hunting, murder and social politics. Peter Marler and others working on the natural communication of animals were uncovering exciting parallels to human speech and language. And a group of psychologists, including the Gardners, were attempting to determine whether apes and dolphins could acquire human-like language and demonstrate human-like thought.

In contrast to studies in the wild, work with these animals took on a cult-like fol-

\section{Is this the origin of art?}

Is art a human invention or an instinct shared with other animals? The work of primate painters this century has been analysed, debated, shown in galleries and sold for high prices. Joni the chimpanzee, seen here with the Russian scientist Nadjeta Kohts in 1913, was the first to be seriously studied. A later chimp called Washoe (see the review above) apparently claimed in sign language that she liked red best because it was beautiful. Is this all just creative play? The ethologist Desmond Morris, who contributes a foreword to Monkey Painting by Thierry Lenain (Reaktion Books, $\mathfrak{£ 1 4 . 9 5 / \$ 2 4 . 9 5 )}$ believes that apes are expressing a primitive aesthetic sense. Read this intriguing account, look at the pictures and decide for yourself.

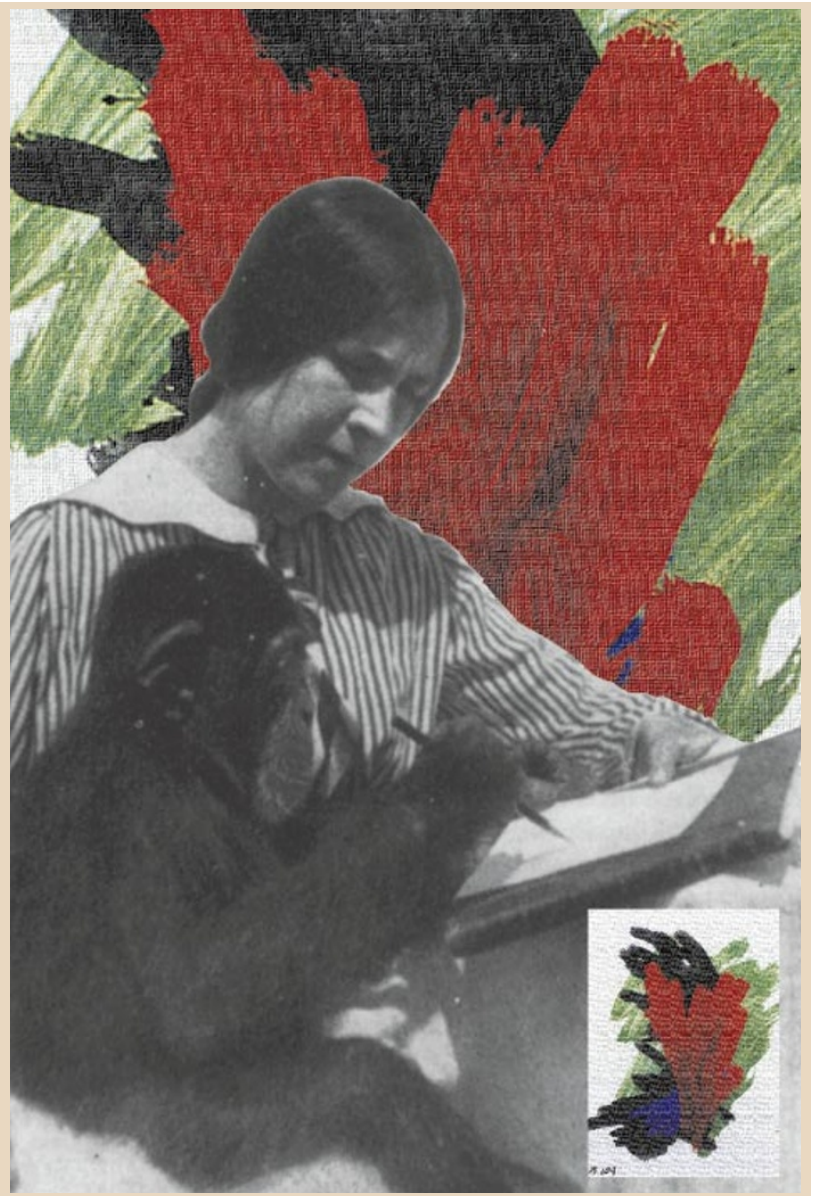


lowing, with ape fan clubs, newsletters, prime-time television spots and so on. Many of the researchers invested years of time and energy - as well as emotional attachment in their studies. Indeed, their subjects were sometimes treated not so much as targets of scientific investigation but rather as family members. It is this paradox that lies at the heart of Fouts's story.

At the start of Next of Kin, Fouts mentions the ethical problem of raising a human child in a chimpanzee family. But then, as if the ethical concerns evaporate, he swiftly turns to the fascination of raising a chimpanzee in a human family, and his own childhood "experiments" with cross-fostering ducklings to domestic cats. After spending years experimenting with Washoe and several other chimpanzees, though, he suddenly realizes he has done something unethical. Driven only by his intellectual curiosity, he has failed to consider what such experiences would be like for a chimpanzee held captive without maternal nurture, sex, play, social politics and so on. Fouts retreats from science and plunges into alcoholism

He eventually emerges from his depression with a renewed sense of energy, guided by a desire to uncover, and ultimately abolish, what he perceives as an international disaster: highly inappropriate housing facilities for primates. The rest of the book tells of Fouts's fight for the care and well-being of primates in captivity, of his continued struggle with research and of the findings that emerged from his studies.

Sociopolitical saga apart, there are various scientific nuggets dispersed throughout the book. The reader is treated to observations of chimpanzees teaching their young bits of ASL, deceiving Fouts for a Coke, signing about the grief of losing a baby, using mirrors to put on make-up and clothes, and signing among themselves about the day's events. One cannot help but be amazed by all of this. Yet Fouts is out of touch with several areas he discusses, and apparently forgets that his research rests on that of others. For example, we find no mention of Premack's work with chimpanzees. Uniquely for his time, Premack focused on the conceptual abilities of animals rather than their capacity to acquire the formal structure of language; it was in this guise that Premack mocked the imaginary syntax-carrying chicken.

And, as it turns out, this is precisely where work on captive apes and other animals has moved, due in part to the critical blows dealt by linguists, psycholinguists and philosophers to studies of ape semantics and syntax. Tetsuro Matsuzawa is also not mentioned and Sue Savage-Rumbaugh, one of the leaders in this field, receives a one-sentence nod. And yet, like Premack, both have generated fantastic findings about the conceptual abilities of chimpanzees and bonobos.

Next of Kin is also replete with conceptual

\section{New in paperback}

\section{Memory Distortion: How Minds, Brains and Societies Reconstruct the Past} edited by Daniel L. Schacter

Harvard University Press, $\$ 17.95, £ 11.95$

"Provides an outstanding multidisciplinary perspective on memory accuracy", Martin A. Conway, Nature 380, 214 (1996).

\section{Atmosphere, Climate, and Change}

by Thomas E. Graedel and Paul J. Crutzen

W. H. Freeman/Scientific American Library,

$\$ 19.95, £ 15.95$

"A wonderful introduction to the intricacies of a modern science relevant to serious questions confronting humankind", P. Brimblecombe, Nature 375, 202 (1995).

\section{The Most Beautiful Molecule: The Discovery of the Buckyball}

by Hugh Aldersey-Williams

Wiley, $\$ 16.95$

"Very well-written and rewarding... an excellent account", Philip Ball, Nature 372, 514 (1994).

\section{Science at the Bar: Law, Science, and Technology in America}

by Sheila Jasanoff

Harvard University Press, \$17.95, £11.95

"This is a perceptive and elegantly written book on how science and law interact both to produce knowledge and to resolve conflict", George J.

Annas, Nature 379, 501 (1996).

and empirical inaccuracies. Fouts thinks that human language is primarily a cultural phenomenon. Given all the evidence of dedicated linguistic brain areas, universal grammar, highly constrained sequences of language development and so on, one simply cannot ignore the importance of biology. He argues in favour of human languages emerging from a gestural form, a claim soundly rejected by many authors, including Steven Pinker, Derek Bickerton and Philip Lieberman. If gestural languages were dominant, why don't we see any remnants today? Why has no culture ever taken a gestural form of language as its first and dominant form of communication? Why aren't gestural signals dominant to vocal signals in most nonhuman primates?

Fouts claims that the dominant form of communication for human infants is through facial expressions and hand gestures, rather than vocal signals, because human infants are born with a chimpanzeelike vocal tract that does not become fully adult-like until about two to three years of age, when words are strung together into sentences. None of this is correct. Infants cry from birth and soon after begin to make communicative gurgles, raspberries and laughing sounds. Babbling emerges at just about the age that the larynx descends into
Time's Arrow and Archimedes' Point: New Directions for the Physics of Time by Huw Price

Oxford University Press, £9.99

"An attempt to grapple with the... problems of the arrow of time with a high degree of analytical care”, John D. Barrow, Nature 383, 228 (1996).

\section{Stars as Laboratories for Fundamental Physics: The Astrophysics of Neutrinos, Axions, and Other Weakly Interacting Particles}

by Georg G. Raffelt

Chicago University Press, $\$ 42, £ 33.50$

"An extensive and expert review... a detailed compendium of results for the serious student", Michael L. Cherry, Nature 384, 128 (1996).

The Most Beautiful Molecule: The Discovery of the Buckyball

by Hugh Aldersey-Williams

Wiley, $\$ 16.95$

"Very well-written and rewarding... an excellent account", Philip Ball, Nature 372, 514 (1994).

\section{Bright Paradise: Victorian Scientific} Travellers

\section{by Peter Raby}

Princeton University Press, $\$ 14.95$

"Extremely readable", D. E. Allen, Nature 383, 491 (1996).

the throat, forming the adult-like configuration. The visual and auditory modalities are used for communication in early development. When words are strung into sentences, it is not because of a mature vocal tract, but because of a computational mechanism sufficiently developed to allow recombination.

Further, Fouts's view that all primate vocalizations (that is, those produced naturally as part of the species-typical repertoire) are processed by the emotional areas of the brain is also incorrect, as demonstrated by recent neurophysiological studies on rhesus macaques showing involvement of the auditory cortex.

The book is therefore both fascinating and infuriating. Fascinating because it tells of the trials and tribulations of trying to communicate with another species. Infuriating because the distinction between evidence and impression are blurred, and because profound philosophical and psychological problems are often dealt with superficially. In the acknowledgments, Fouts showers "thank-yous, hugs, and pant-hoots ... to the five people who inspired [the] book: Washoe, Loulis, Moja, Tatu, and Dar". People? How interesting.

Marc D. Hauser is in the Departments of

Psychology and Anthropology, Harvard University, Cambridge, Massachusetts 02138, USA. 
atheoretical diagnostic language — is thus given further support.

While denying that they are 'antipsychiatry', Kutchins and Kirk do deplore the proliferation of psychiatric labelling, facilitated by DSM's ever-lengthening diagnostic list. Nowadays many groups, and not just psychiatrists, patently have an interest in translating everyday behaviours into psychiatric diseases - worry for example becomes "generalized anxiety disorder".

In this medicalization process, the wretched and the powerless are all too easily further victimized by labels that carry a lasting stigma. One solution, of course, would be for the public acceptance, without shame, of mental disorder. But that would be crying for the moon.

This is a serious and well-documented study, which casts serious doubt on the touted scientific status of DSM categories. It is also readable, although Kutchins and Kirk's preoccupation with the day-to-day minutiae of the politics of naming may dispose some psychiatrists to see in this a case of ancient obsessional disorder. It is certainly sobering to discover just how the terms we take for truth have come into currency.

Roy Porter is at the Wellcome Institute for the

History of Medicine, 183 Euston Road, London

NW1 2BE, UK.

email:r.porter@wellcome.ac.uk

\section{Where has the billion trillion gone?}

\section{The Conscious Universe: The Scientific Truth of Psychic \\ Phenomena}

by Dean I. Radin

HarperEdge: 1997. Pp. 320. \$25.

\section{I.J.Good}

My friend Christopher R. Evans worked for a time with the well-known parapsychologist J. B. Rhine, but became a sceptic. In 1974 I invited Evans to Blacksburg, Virginia, to give a lecture on extra-sensory perception (ESP), and picked him up at Roanoke airport. $\mathrm{He}$ had travelled from London in a Boeing 727. The licence number of my car happened to be CRE 727. The probability of that coincidence was about $1 / 26^{3} \times 1,000 \approx$ $1 / 17,000,000$.

I have experienced three even more remarkable coincidences, one of which changed the course of my life. But I doubt whether these coincidences were paranormal because there are more than 5 million minutes a decade. Some people must have experienced chance coincidences with probabilities of about $10^{-14}$. So controlled, not anecdotal, observations are needed.

In England, for about 20 years starting in 1939, S. G. Soal was by far the most promi-

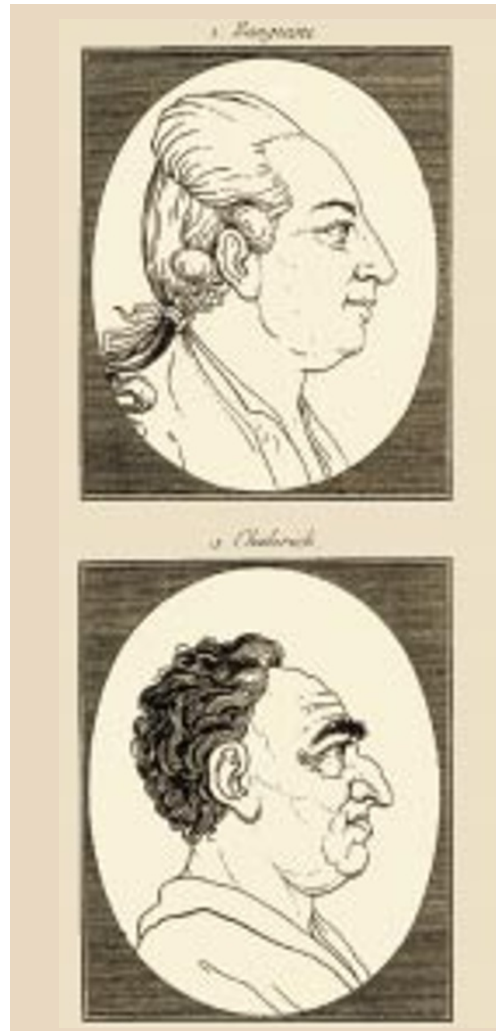

\section{Body language}

Facial features of the sanguine, phlegmatic, melancholic and choleric personality types (clockwise from top left), taken from Johann Lavater's Essays on Physiognomy (1789). They are reproduced in Believing in Magic: The Psychology of Superstition by Stuart A. Vyse

nent parapsychologist. He did controlled card-guessing experiments resembling those of Rhine. At the suggestion of Whateley Carington, Soal examined his records, looking for 'hits' one ahead and one behind the guess of the 'current' card. In one series of experiments, the tail probability, or $P$ value (the probability that, by chance, the outcome would be at least as 'extreme' as the observed outcome), was $10^{-35}$ for the 'one-aheads', thus seeming to prove the existence of precognitive telepathy.

But evidence accumulated, culminating in the ingenious detective work of Betty Markwick in 1978, showing that Soal's studies were very probably fraudulent. Dean Radin, author of The Conscious Universe, avoids mentioning Soal.

Radin is firmly convinced that paranormal events happen. His conviction is based mainly on evidence from controlled experiments but is influenced also by the "nonlocal' phenomena of quantum mechanics.

Quantum mechanics has affected many people's metaphysical speculations about consciousness and ESP. For example, some 50 years ago, in a conversation with the prominent physicist Léon Rosenfeld about subjective experiences, I said: “A [quantum]

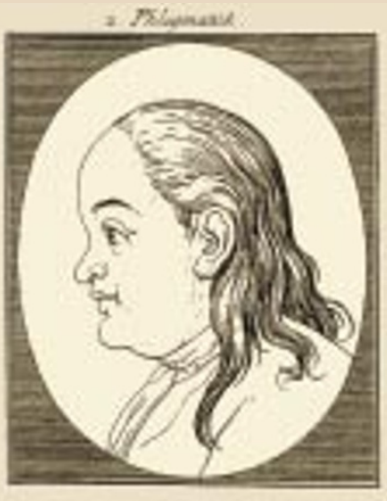

W. Vhably

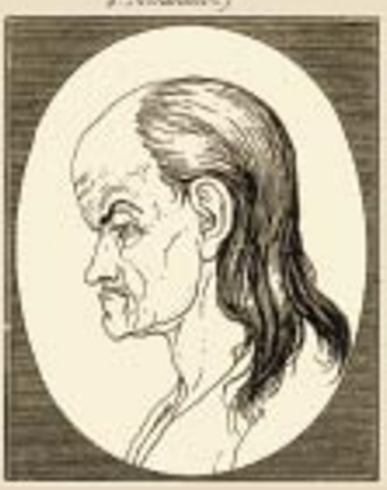

(Oxford University Press, £18.99, \$25). Vyse argues that scientific analysis of differences in personality traits - such as sensitivity to coincidence, fear of failure, a need for control can help us to understand why superstition and belief in the paranormal are so prevalent today.

field theory does seem to be natural in order to understand how the activities of numerous neurons in a brain somehow summate. Perhaps psi depends on $\psi$ [the Schrödinger wave function]."

Leaving psi aside, there are much more serious and technical speculations about the relationship between consciousness and quantum fields by Stuart Hameroff and Roger Penrose, related to microtubules extremely small skeletal elements in neurons. One could say that microtubules update Descartes' pineal gland. Penrose does not, however, mention ESP in his work on consciousness.

Taken at its face value, some of the evidence from controlled experiments is conclusive. But we have to allow for fraud and the 'file-drawer' effect. Take the first of these. Even many 'normal' scientists have cheated, as recorded by Alexander Kohn in False Prophets: Fraud and Error in Science and Medicine (Barnes and Noble, 1986). To that collection may be added the psychologists who lie to their subjects and call the lying 'experimental dissimulation'.

Parapsychologists and psychics have more incentive to cheat because, if their research results are uninteresting, they have 
less opportunity to turn to teaching. Unconscious cheating, wishful thinking (which is universal), unsound experimental design and analysis, and seeing what we expect are further pitfalls. The statistician M. G. Kendall once described the phenomenon of seeing what one expects as "one of the deadliest forms of bias in psychology". He was referring to an experiment in which an observer of a reliable random-number generator had a tendency to write down too many even numbers.

Potentially the most important evidence in Radin's book is in the chapter on metaanalysis, which is also emphasized in the introduction - and it is here that the 'filedrawer' effect comes into play.

Meta-analysis is the combination of results from many experiments. A problem in meta-analysis, and in statistics generally, is how to allow for the researches that remain unpublished and unknown because their $P$ values did not reach a conventional significance level such as 0.05 . I do not know who coined the name 'file-drawer' effect for this problem. This effect drags down the statistical significance of published work. Radin claims that "parapsychologists were among the first to become sensitive to this problem" - although he does not say when - and he mentions that "in 1975 the Parapsychological Association's officers adopted a policy opposing the selective reporting of positive outcomes". The problem was known to statisticians by 1958 .

Consider the following typical example. Radin points out that there were 186 publications on ESP card tests worldwide from 1882 to 1939 . "The combined results of this four-million trial database [taken at face value]," he says, "translate into tremendous odds against chance - more than a billion trillion to one." (A 'trial' is the guess of one card.) He means that the $P$ value is about $10^{-21}$ - he is not writing only for the scientific establishment. This $P$ value corresponds to a bulge above 'chance' expectation of $9.5 \sigma$, where $\sigma$ is the standard deviation. (I call that a 'sigmage' of 9.5.)

Apart from the possibility of conscious and unconscious fraud and wishful thinking in some fraction of the publications, Radin claims, with no explanation, that, in order to "nullify" the statistical significance, the file drawer would have to contain "more than 3,300 unpublished, unsuccessful reports for each published report". That number 3,300 is a gross overestimate. It should be reduced at least to about 15 (or even to 8 ).

The expected sigmage in the file drawer, under the null hypothesis, would be slightly negative but I will call it zero. If these results were combined with the published work, the total sample size would be multiplied by 16, thus becoming 64 million individual guesses. Given the null hypothesis ('chance'), the bulge would be unaffected so the sigmage would be divided by $\sqrt{ } 16=4$ and would become $9.5 / 4=2.4$, with a $P$ value of about $1 / 100$.

Because the number of individual guesses is so large, this $P$ value appreciably supports the null hypothesis (no ESP). This is because a Bayes factor (the factor by which the odds of a hypothesis are multiplied in the light of the observations), corresponding to a fixed $P$ value, is roughly proportional to $1 / \sqrt{ } \mathrm{N}$, where $\mathrm{N}$ is the sample size. So Radin's method for evaluating the file-drawer effect, whatever that method may be, must be misguided. This conclusion largely undermines Radin's meta-analysis which is central to his case for ESP.

Nevertheless, Radin's book is well written and provides a good summary of the arguments supporting the existence of ESP, with about 600 references. It is less good on the counter-arguments. Readers should also consult ESP and Parapsychology: A Critical Evaluation by C. E. M. Hansel (Buffalo, 1980), where much fraudulent work is exposed. Radin quotes Hansel as saying that three $P$ values, each of 0.01 , amount to one of $10^{-6}$, and that he (Radin) would find that convincing. But the product of independent $P$ values is not a $P$ value. The product has to be transformed by a method due to $\mathrm{R}$. A. Fisher. Both Hansel and Radin have overlooked this. In the present example, the composite $P$ value is $1 / 9,000$, not $1 / 1,000,000$.

I am not a sceptic by definition. There is one type of experiment that could convince me if it were successful. Guesses, by psychics, of the parities (even or odd) of future cricket scores could be published on the World Wide Web. The actual scores and parities could be published (later) in large print to help the

\section{Toy review Smaller, cheaper, more plasticky}

With Christmas still months away, and the latest Mars landing already fading in the memory, it is a good time to draw your attention to this scientific stocking-filler. In collaboration with the US Jet Propulsion Laboratory, Mattel has brought out the "Mattel Hot Wheels JPL Sojourner Mars Rover Action Pack Set".

This is a set of three small plastic models: the Pathfinder spacecraft in transit, with removable heat shield and tiny lander; a larger-scale version of the lander, with foldable panels and removable rover; and a larger-scale-still Sojourner rover. The rover is undoubtedly the star, with sprung 'rocker-bogey' suspension that allows it to take up all sorts of cute rock-sniffing postures.

The Nature review copy of the Mattel Hot Wheels JPL Sojourner Mars Rover Action Pack Set has now completed its primary mission objectives, successfully demonstrating the technology involved in operating for several weeks on top of a computer screen in a harsh environment of editorial curiosity, without suffering any appreciable reduction in its precognizing of the psychics and to help their evaluation. This procedure would rule out the possibility of undetectable fraud.

I. J. Good is in the Department of Statistics,

Virginia Polytechnic Institute and State University, Blacksburg, Virginia 24061-0439, USA.

\section{Dangerous liaisons}

\section{Menachem's Seed}

by Carl Djerassi

University of Georgia Press: 1997. Pp. 196. $\$ 21.95$

\section{Jack Cohen}

This is the third novel in a series of what the chemist Carl Djerassi calls "science-infiction" in which everything mentioned could or does exist. "Most of my characters, fictional as well as real, are scientists," he says. "By exposing their lives, I try to make comprehensible the culture and behaviour of scientists."

There is a similar, specialized genre on the fringes of modern science fiction - stories about fictional scientists like fictional detectives or even fictional cowboys. Carl Sagan's Contact is a well known example, but Gregory Benford's Timescape or Artefact, Greg Bear's Blood Music, as well as Nigel Kneale's older Quatermass series or even E. E. 'Doc' Smith's archaic Lensman all come to mind as fiction about scientists. Science-infiction, however, seems to be less exciting and to have fewer possibilities.

I reviewed elsewhere the first of Djerassi's novels, Cantor's Dilemma, and recom-

mended it, 1

mainstrean 